\title{
Prevalence of Sexual Harassments and Their Association with Psychological Distress among Pharma College Female Students, Southern, Ethiopia: 2018
}

\author{
Kaleab Tesfaye Tegegne, MPH $^{1} \quad$ Eleni Tesfaye Tegegne, MPH $^{2} \quad$ Mekibib Kassa Tesemma, MPH ${ }^{3}$ \\ 1.Health Science, Hawassa health science college, Hawassa, Ethiopia \\ 2.Health Science, Gondar University, Gondar, Ethiopia \\ 3. Institute of Tropical Medicine (ITM), in Collaboration with University of Gondar, Gondar, Ethiopia
}

\begin{abstract}
Background: a number of studies conducted on sexual harassment focused on general magnitude rather than the specific details of the various forms of sexual harassment and their effect on psychological health. Thus, the objective of this study is to assess the various forms of sexual harassment and their association with psychological distress among Pharma College female students.Methods and Materials: Institution based cross sectional study was conducted among female students of Pharma College from 01/06/2018 to 30/08/2018G.C. Stratified random sampling technique was employed to recruit 385 students. A pretested and structured self-administered questionnaire was used. After collection the data was checked for completeness, cleaned, coded, entered and was analyzed using SPSS-21 version software. Descriptive statistics including frequencies, percentages, and standard deviations was used to describe findings. The presence of association between dependent and independent variables was assessed using Adjusted Odds Ratio (AOR) and 95\% confidence interval (CI). Associations of independent variable with $\mathrm{p}$-value $<0.05$ was considered statistically significant.Result: The prevalence rates of physical, verbal and nonverbal sexual harassments were $22.1 \%, 38.4 \%$ and $17.1 \%$, respectively, while the prevalence rate of psychological distress among students who had experienced sexual harassment was $36.3 \%$. The multivariable logistic regression analyses indicated that students monthly income $<500$ were 2 times more likely to be physically [adjusted $\mathrm{OR}=4.787,95 \% \mathrm{CI}=(2.127,10.773)$ ] and verbally [(adjusted $\mathrm{OR}=4.151,95 \% \mathrm{CI}=$ $(2.246,7.671]$ harassed than those in monthly income 500-999.Conclusion and Recommendation: The prevalence of various forms of sexual harassment were higher and strongly associated with psychological distress. Important implications for college officials and policy makers including creating harassment free institution have been drawn. Otherwise, female students tend to dropout and their academic achievements suffer a lot as a result of psychological distress; and the government's effort for realizing the gender parity in education would be compromised.
\end{abstract}

Keywords: Verbal sexual harassment, Nonverbal sexual harassment, Physical sexual harassment and Psychological distress.

DOI: $10.7176 / \mathrm{JNSR} / 9-7-05$

Publication date: April $30^{\text {th }} 2019$

\section{LIST OF ACRONYMS}

AAUW-American Association of University of Women

DSM-IV- Diagnostic and Statistical Manual for Mental Disorders

EEOC- Equal Employment Opportunity Commission

ILO- International labor organization

SNNPR- South Nation and Nationalities People regional state

SPSS -Statistical Package for Social Sciences

TTC- Teachers training college

USA-United States of America

WHO -World Health Organization

\section{INTRODUCTION}

1.1 Background

Despite the lack of a single meaning, sexual harassment is commonly defined as unwanted and unwelcome sexual behavior in a work or educational setting affecting both physical and psychological well-being of a person. It could be evident in three different ways: verbal, physical and nonverbal forms verbal sexual harassment includes unwanted sexual suggestions, jokes, and offensive comments. Nonverbal sexual harassment includes unwelcomed sexual winking, showing sexual gestures, and displaying sexual materials. And physical harassment includes unwanted sexual touching, attempting to kiss and attempting to rape someone (1).

Psychological distress is defined as an experience of an individual which is unique and discomforting and which is a result of a certain stressor or demand that may cause a temporary or permanent harm to the individual 
(2).

Since women and girls are very crucial and significant members of any society in the world, they should be provided with a living, working and educational environment which is safe and protected from different kinds of abuses so that they could be productive and contribute to their community in whatever fields they choose to study or work. A person who does not have a sense of security, physical protection and psychological well-being may not be able to be productive and successful. The emotional well-being and academic success of those students who have been the victims of sexual harassment have been affected negatively by the sexual harassment they faced throughout their college and university years (3).

A number of studies indicated that sexual harassment against women is the most common problem globally and locally. A WHO report pointed out the problem has increased over the past 25 years impacting on women's physical and psychological well-being profoundly in all settings

(4). However, sexual harassment is much more common in educational settings. A survey study in a school in America revealed that more than $80 \%$ of female students had experienced sexual harassment at least once in their school life, and also more than one-third of college female students had been victims of sexual harassment when they were first year students $(1,3)$.

With respect to the prevalence of sexual harassment in Ethiopian Universities, 35\%, $41.8 \%$ and $42 \%$ of Bahirdar, Addis Ababa, and Jimma Universities' female students, respectively, reported that they had experienced sexual harassment (5, 6 and 7). Similarly, a recent study conducted at Jimma University showed that $83 \%$ of female students were victims of sexual harassment (8).

There are few local studies, to the researchers' knowledge, that documented the relationship of sexual harassment and female university student's psychological distress in the Ethiopian context. A study carried out at Bahirdar University showed that $93.6 \%$ of victims of sexual harassment did not share the incidents for anybody which undoubtedly worsened their psychological well-being (5).

\subsection{Statement of the problem}

Sexual harassment is one of the sexual abuses that women and girls face throughout the world in their working and educational settings. According to the study of Association of American University of Women (AAUW) study on sexual harassment on American college and university students, from about 10 million undergraduate students about 6 million students will be sexually harassed during their stay at the colleges and universities (2).

A study conducted by Addis Ababa University, facing gender based violence was a very common problem of female college students. In this study, among 1024 female college students in Mekelle town in Northern Ethiopia, $62 \%$ of the females that participated in the study reported being life time victims of gender based violence, $46.8 \%$ during their stay in college, and $40.2 \%$ during the year in which the research was conducted. The study also revealed that verbal harassment and unwanted intentional body contacts were considered as the normal part of the participants 'lives. According to Joseph, the integrity of academic environment will be disrupted by sexual harassment. He stated that sexual harassment is a problem in educational settings that is underreported and under researched (9).

Most studies on sexual violence in Ethiopia tend to focus on studying the most serious kinds of sexual violence like rape, attempted rape and sexual coercion which may cause a visible physical and psychological problem. But Sexual harassments like verbal abuse, displaying pornographic and sexual materials forcefully and indecent sexual touching are not usually studied well and are not given attention. These kinds of sexual harassments may not bring a visible physical problem on the victims, but the psychological problem they may cause a damaging effect to the victim.

The invisible psychosocial effect of violence on girls has the most negative and enduring effects on girls. Losing one's self-esteem, feeling of rejection and lack of self -worth are among the major negative consequences that girls who face sexual, physical \& psychological violence experience (10). Since students encounter verbal harassment and unwanted intentional body contact frequently, many female students consider it as the normal part of their lives. But the researcher of the current study argues that the frequently happening of sexual harassment does not make it normal.

As long as it is causing psychological problems on the girls and as long as it has negative effect in their educational success, it should not be considered as normal. The issue of sexual harassment should be given due attention by researchers, the victims themselves, perpetrators and authorities so that the problem could be addressed.

Our curiosity to study sexual harassment of female students in their educational setting and its psychological consequences on females arises from the fact that as most of students are female student, they faced sexual harassment several times from peers and teachers throughout their high school and university years. This study was conducted based on this consideration hoping to suggest possible solutions based on the results of the study. And to knowledge and access of the researcher no such study had been conducted to study sexual harassment in Pharma college female students. 


\subsection{Significance of the study}

Ethiopian population is consisted of a significant number of youths including adolescents which implies that there is a need to make this age group an area of study, policy formulation and application. Giving focus to this age group means giving focus to the larger portion of the population which will be important for the improvement of the life of these age groups and the development of the country at large. And since girls cover significant number of the adolescent and youth population, their problems and issues should be given due attention and need to be addressed. Since, a huge number of girls enroll in colleges every year, it is important to study their actual situations and help them to get the education they need in a free, comfortable and healthy environment.

A number of studies conducted worldwide and locally on sexual harassment usually focused on the prevalence of sexual harassment in general. They failed to address specifically the prevalence rates of physical, verbal and nonverbal harassments and their association with psychological health. Even if there are several researches conducted on sexual harassment in many developed countries, a lesser amount of researches are conducted in developing countries including Ethiopia. In Ethiopia, few researches are conducted which made sexual harassment the main topic of their research. So, there is a need to study the issue in different contexts and settings including educational settings.

Thus, this research attempted to fill the gaps pertaining to the prevalence of the various forms of sexual harassments and their association with psychological distress. This study is believed to contribute by showing the current situation of sexual harassments of female students in Pharma College, to serve as a reference for a researcher who wishes to conduct a research on similar issue and to be an input for policies, strategy and laws that try to address the issue of sexual harassment and to suggest possible solution for the problem according to the results of the research.

The finding of this research is also expected to motivate other researchers to study the situation in other learning institutes that will add to the existing data and initiate nationwide measures to address the issue.

\section{LITERATURE REVIEW}

\subsection{Sexual harassment}

There is no one universal and single definition of harassment that works throughout the world. Different experts, legislations, policies and the lay person define sexual harassment in different ways. Even if there may be some variations on how experts, the law and individuals define sexual harassment, the definitions they give have many features in common. Usually they commonly define sexual harassment as unwanted, unwelcomed, inappropriate, and offensive behavior, which usually involves the abuse of unequal power derived from the institutional, cultural background and gender structure $(11,12$ and 13$)$.

Sexual harassment is defined legally by legal bodies and it is also defined empirically by researchers and experts on the issue. The most widely used and pioneer of the legal definition of sexual harassment was given by the EEOC (Equal Employment Opportunity Commission) or the office of civil rights in the United State in 1980. EEOC on Title VII of its guideline, described sexual harassment as a kind of sex discrimination and unlawful employment practice. Two categories of sexual harassment were provided by the EEOC which are: quid pro harassment and hostile environment harassment. In quid pro harassment, the harasser usually offers some kind of benefits for getting sexual favor in return or the harasser promises the removal of some kind of harm or a threat for a sexual favor. And hostile environment harassment includes acts of sexual nature involving behaviors like unwelcomed and unwanted sexual remarks, comments, jokes, physical contact and displaying materials of a sexual content in different circumstances. that is so severe, persistent, or pervasive that it limits a student's ability to benefit from educational activities (14)

AAUW (American Association of University Women) also classifies sexual harassment as quid pro quo harassment that involves requests for sexual favors, generally by a school employee to a student, in exchange for some type of educational benefit. And the second type hostile environment harassment according to AAUW involves harassing sexual conduct that is so severe, persistent, or pervasive that it limits a student's ability to benefit from educational activities (15).

According to the UN general, sexual harassment is defined as unwelcomed and unwanted sexually determined behavior, physical contact and advances, sexually-colored remarks, showing of pornography and sexual demands, whether by words or by actions that constitutes a health and safety problem, which when objected could disadvantage the victim in her connection with her studies, including recruitment or promotion, or creates a hostile study (16).

\subsection{Psychological distress}

Defining psychological distress has always been a controversial issue for researchers. According to the DSM-IV (Diagnostic and Statistical Manual for Mental Disorders-IV) psychological distress is a psychological or mental problem that may exhibit symptoms like depression, hopelessness, anxiety, fear, boredom and lack of sleep which may be caused as a result of a stressing situation that an individual had faced (17). 
Psychological distress is also defined as an experience of an individual which is unique and discomforting and which is a result of a certain stressor or demand that may cause a temporary or permanent harm to the individual (2).

\subsection{The magnitude of sexual harassment}

\subsubsection{The prevalence rate worldwide and in Africa}

According to the research conducted on the outcome of sexual harassment and bulling on high school students in USA, sexual harassment aggravated sexist and heterosexist stereotypes which decreased the school engagement of students, distanced students from their teachers and negatively affected academic achievements of students (18).

Sexual harassment in education is higher in countries with weak educational system, which has less level of accountability, high levels of poverty and gender inequality (19).

In a study conducted in the United Kingdom, $50 \%$ of the students believe that sexual harassment of students is prevalent in the universities of United Kingdom (20)

According to the study of female students in Pakistan Universities (like the University of Peshawar), are sexually harassed by their senior teachers and heads of various departments. In

many African countries, sexual harassment of female students by male students and instructors include degrading sexual verbal remarks, undesired physical contact or other type of gender based violence (21).

In a study conducted in Kenya in the University of Nairobi, female students carry the burden of sexual harassment in their shoulders. According to the findings of this study, because of the fear of sexual harassment, female students do not move freely in the campus, they also withdraw from programs and they sometimes do not use available facilities in the campus in order to avoid the incident of sexual harassment. As a result of this, females tend to be in a disadvantaged position in the campus compared to their male peers (22).

In Ghana both traditional and contra power forms of sexual harassment are prevalent in public Universities and professional institutions. It is also reported that women are more likely than men to be sexually harassed in medical school of Ghana (21).

In another study conducted in Ebonyi state University of Nigeria, among 295 female students, 108(36\%) of them had experienced sexual harassment at least once in the campus and $35(32.4 \%)$ of the female students experienced forced sexual intercourse, $73(67.6 \%)$ of them experienced other forms of unwanted sexual contacts including indecent touching, romance and kisses. According to the study, majority of the perpetrators were fellow male students (21).

\subsubsection{The prevalence rate in schools, colleges and universities of Ethiopia}

In a research conducted in Jimma University, among 385 female students, the prevalence rate of physical harassment (e.g. unwanted sexual touching, unwanted kissing) was 78.2\% and verbal harassment (e.g. unwanted sexual comment, offensive jokes) was $90.4 \%$ and non-verbal harassment(e.g. showing unwelcomed sexual materials, sexual gestures) was $80.0 \%$ (23).

A study conducted in Ambo secondary and preparatory school students, among 414 female students, 35\% of the female students had experienced sexual harassment throughout their school life and 33.3\% of them had experienced sexual harassment in the 12 months prior to the study. $47.8 \%$ of the females had experienced verbal sexual harassment and $35.5 \%$ of the students had experienced physical sexual harassment. In the study the most frequent kind of sexual harassment was repeatedly told sexual stories or jokes $(50.7 \%)$ followed by getting comments on

sexual life (47\%); being repeatedly asked for date, drink or dinner even when refused (46.4\%); encountering several attempts to establish romantic relationship despite efforts to discourage $(45.7 \%)$ and getting offensive remarks about appearance or body (44.2\%) (24).

Another study of sexual harassment in Jimma University participated 304 female students and according to the results of the study, $50 \%$ of the study participants reported that they had experienced insistent request to establish romantic relationship despite their efforts to discourage the person; $45 \%$ indicated that they had been repeatedly asked for dates, dinner or drink even when they said nno'; 43\% reported that they were touched in a way that made them uncomfortable; $35 \%$ reported that men had made attempts to stroke or fondle them, and $30 \%$ revealed that they have encountered attempts of drawing them into unwanted discussion of personal or sexual matters (7).

A study in Wolayita Sodo University in Southern Ethiopia revealed that among 374 female students $18.7 \%$ of them had experienced verbal harassment; $11.3 \%$ of them had faced forced sexual initiation, and $8.7 \%$ had experienced completed rape. The study further revealed that $42 \%$ of the victims from the total female participant had experienced violence while they were in high school and during their first year stay at the university, while $11.1 \%$ were violated while in their second and third year of their study at the university (25).

A study in Mekelle University of Adi Haki campus in 2016, female students were the targets of sexual harassment in the campus, male instructors being the perpetrators most of the time. The research also reported that females who are harassed prefer to deal with sexual harassment informally by confronting the victims by their 
own, telling to a friend, normalizing the behavior or by ignoring the behavior and only very few of the students reported the sexual harassment they faced to the university gender office or to the authorities (26).

In another study conducted in Arbaminch town in Gamo Gofa zone, among 369 female students who participated in the study, the prevalence rate of sexual harassment was reported to be $40.1 \%$ for verbal harassment followed by caressing breasts and the genitalia (28.7\%), and unwelcome kissing (29.3\%) (27).

According to Mamaru et al, sexual harassment has a significant relationship with the colleges that the female students attended. Female students who were in College of Public Health and Medicine were three times more likely to be physically harassed than those females who were attending the College of Social Science and Law (23).

\subsection{Factors associated with sexual harassment}

According to WHO report age is the most important risk factor for being a victim of sexual violence. Young women are usually found to be more at risk of rape than older women (28). For example, national survey in nine countries found a consistent association of an increased risk of partner abuse for women with low educational attainment, being under 25 years old, having witnessed her father's violence against her mother, living in an urban area, and having low socioeconomic status. Also in a study in the northern west Ethiopia, the age range of performed rape victims was between 12 and 21 years (29).

Increased vulnerability to sexual violence also stems from the use of alcohol and other drugs. Consuming alcohol or drugs makes it more difficult for women to protect themselves by interpreting and effectively acting on warning signs. Several studies in developing countries have also found a strong association between consumption of alcohol or drugs and the risk of violence. Drinking alcohol may also place women in settings where their chances of encountering a potential offender are greater $(30,31)$. A lot more school based Studies from Ethiopia also indicated the association of alcohol consumption and sexual violence. Reports from Jimma and Agaro town among female youth found significant associations between sexual violence and regular alcohol consumption $(32,33 \&$ $34)$.

The WHO report shows that violence impacts certain groups disproportionately. Poverty increases people's vulnerabilities to sexual exploitation in the workplace, schools, and in prostitution, sex trafficking and the drug trade. People with the lowest socioeconomic status are at greater risk for violence. Poor women and girls may be more at risk of rape in the course of their daily tasks than those who are better off, for example when they walk home on their own from school late at night. Poverty forces many women and girls into occupations that carry a relatively high risk of sexual violence (28).

\subsection{Psychological Consequences of sexual harassment}

According to ILO (International Labor organization), sexual harassment causes serious psychological problems. ILO reports that persons who experienced sexual harassment fear that people will talk behind their back, afraid of losing trust in other people and live in shame (34).

Because of sexual harassment $17.6 \%$ of female students in Jimma University dropped out from the University (35). In a similar study in Addis Ababa University on sexual coercion of female students, there was a negative association between sexual violence and academic achievement of female students (36).

A study in female University students who were victims of sexual harassment reported to have several negative psychological consequences like feelings of embarrassment, fear, sleep disturbance, loss of appetite and lowered confidence (7). A similar study in Bahirdar University revealed that sexual harassment or attempted sexual assault was reported by $35 \%$ of the female students as one of the causes of low academic performance (5).

In a study of sexual violence on female students in Mekelle colleges, negative psychological consequences such as fear (77\%), hopelessness (42\%), self-blame (30\%) and feeling of sadness $(24 \%)$, suicidal ideation $(17 \%)$ and suicide attempt (10\%) were reported because of the sexual violence they faced (9).

A study conducted in Jimma university female students the total rate of psychological distress were $60.3 \%$ and the rate of psychological distress among female students who were sexually harassed were $63.3 \%$ ( 23$)$.

\subsection{Conceptual framework of the study}

Based on reviewed literatures the conceptual framework showed in figure 1 below summarizes different factors which may be associated with the prevalence of sexual harassment and psychological distress. 


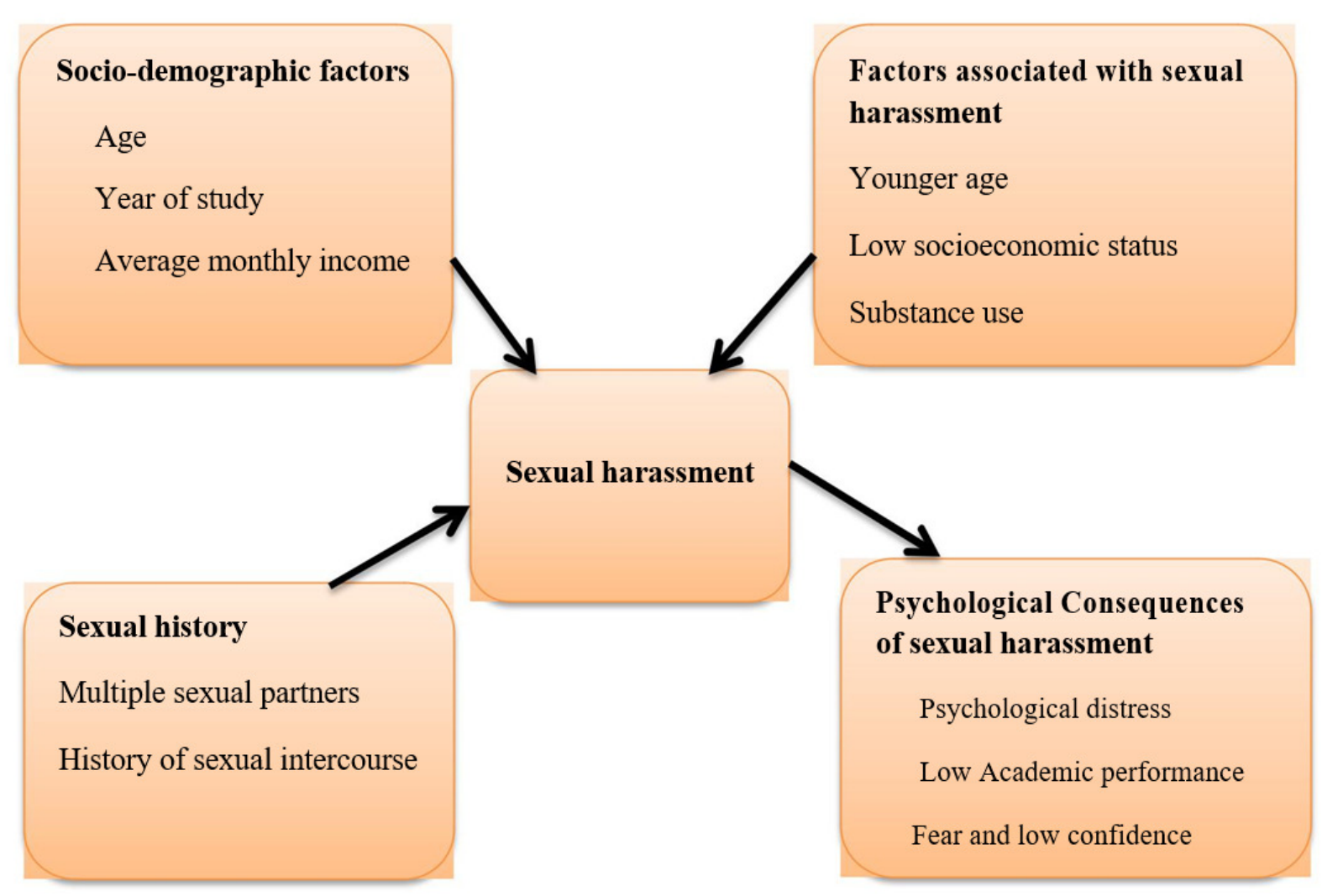

Figure 1: Conceptual framework that shows possible associated factors with sexual harassment and their association with psychological distress (source: developed after reviewing different literatures).

\section{OBJECTIVES}

\subsection{General objective}

To assess the prevalence of sexual harassments and their association with psychological distress among Pharma collage female students.

\subsection{Specific objectives}

To assess the magnitude of sexual harassment

To assess the magnitude of psychological distress

To examine the association between sexual harassment and psychological distress

To identify the socio-demographic factors associated with sexual harassment and psychological distress

\section{METHODS AND MATERIAL}

\subsection{Study Area and period}

The study was conducted from 01/06/2018 to 30/08/2018G.C. in Pharma collage, which is found in Hawassa city. It is located at 275 kilometer south from Addis Ababa. Pharma collage is one of the private collages found in southern nation, nationalities and peoples region (SNNPR). Currently, the collage comprises of degree BSc (HO), BSc (nurse), BSc (pharmacy), BSc (accounting) and BSc (business management). In 2010 academic year a total of 1641 students (female 1026, male 615) are enrolled in the regular programs.

\subsection{Study design}

Institution based cross sectional study design was used.

\subsection{Population}

\subsubsection{Source population}

All students who are registered in 2008-2010e.c academic year in Pharma collage in all departments.

\subsubsection{Study population}

All randomly selected students from all department of the collage was taken as a study population based on academic year. 


\subsection{Inclusion and exclusion criteria}

\subsubsection{Inclusion criteria}

Regular (day time) female students who are present in the collage on the day of administration of questionnaire was included.

\subsubsection{Exclusion criteria}

Students who was not able to complete the questionnaire due serious illness or students who are not willing to participate and male students was excluded.

\subsection{Sample size determination}

The sample size was estimated using sample size determination formula for a single population proportion formula. The sample size was determined by considering assumptions of the proportion of sexual harassment from a recent study among Bahirdar University undergraduate female students was $35 \%$ with a margin of error (d) 0.05 , nonresponse rate 0.1 , with $95 \%$ confidence certainty and alpha 0.05 will considered.

$$
=\frac{2^{2(1-)}}{}
$$

Where $\mathrm{n}=$ sample size

$\mathrm{P}=$ estimated percentage based on past recent study, $35 \%$

$\mathrm{D}=$ allowed error $5 \%$

$\mathrm{Z}=$ the $\mathrm{Z}$-score associated with selected degree of confidence interval at $95 \%$ confidence interval is 1.96 and adding $10 \%$ for non-response rate.

$\mathrm{n}=(1.96)^{2} 0.35(0.65) /(0.05)^{2}=\mathbf{3 5 0}$

Contingency $=\underline{350 \times 10}=35$ (nonresponse rate)

100

When $10 \%$ non-response rate was added $350+35=385$

\section{Therefore, the total sample size was $=\mathbf{3 8 5}$}

\subsection{Sampling techniques and procedures}

Stratified random sampling technique was used to identify participants of the study. To assure the representativeness of the data, the sample size was proportionally allocated to each department on the number of the students and academic year. Stratified sample size $(n=385)$ to each department by probability proportional to size (PPS) based on academic year and department. Finally students was selected by lottery method.

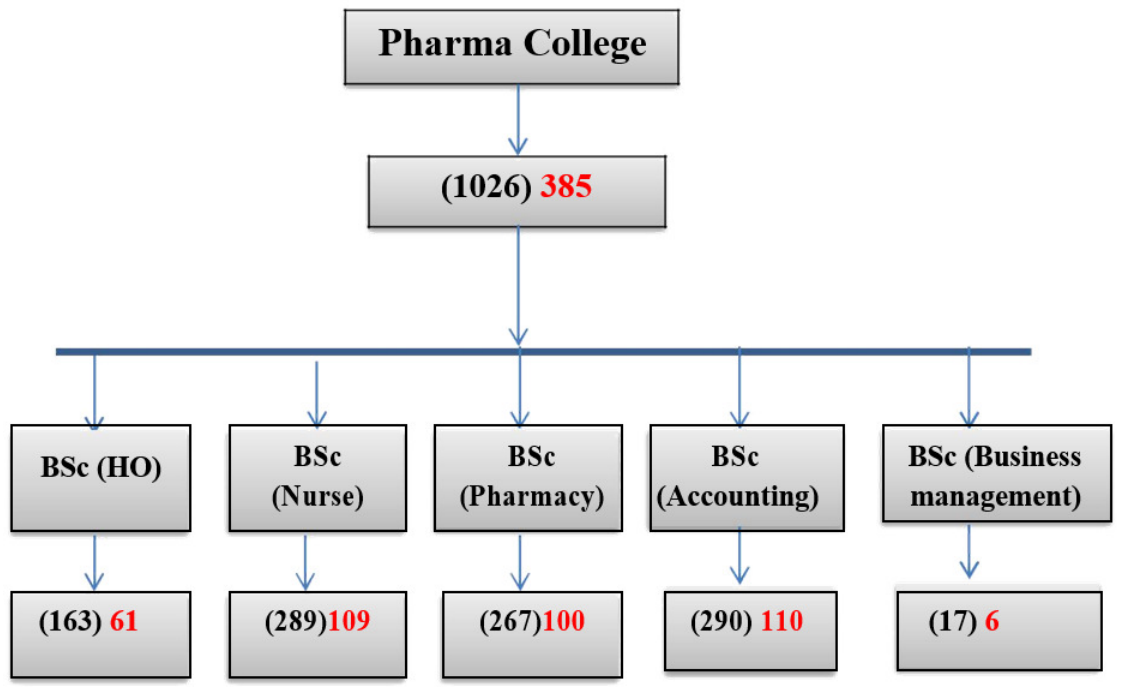

Where;

$(* * *)=$ Subtotal number of female students

$* * *=$ Sampled number of female students

Figure 2: Sampling technique by stratifying the source population using field of study among regular undergraduate female students of Pharma collage.

As explained above, the stratification was going down in the perspective year of study as described in the following table 1 below. 
Table 1: Proportional allocation of the sample in the perspective year of study among regular undergraduate female students of Pharma collage.

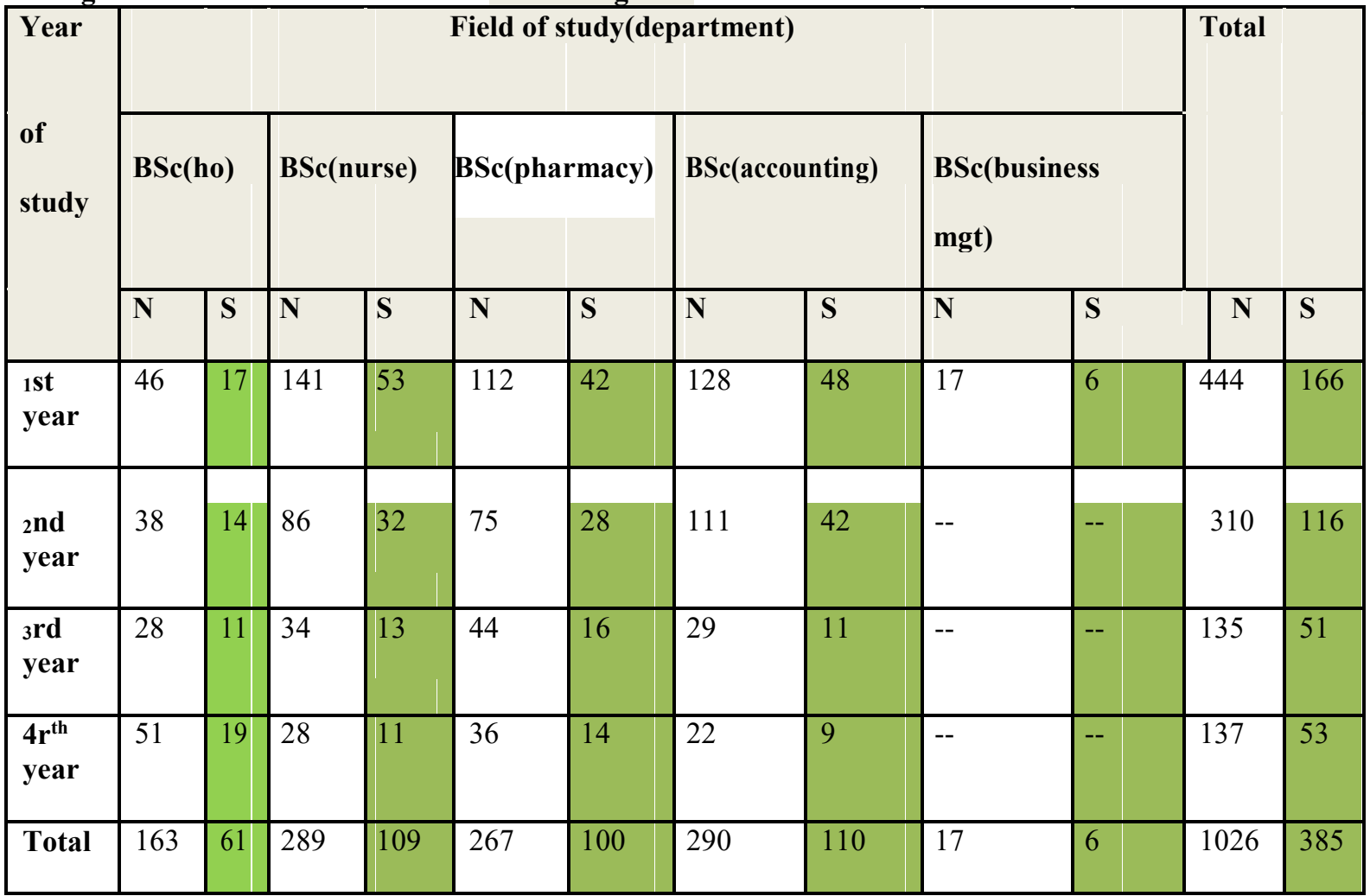

Where;

$\mathrm{N}=$ Subtotal number of female students

$\mathrm{S}=$ Sampled number of female students

\subsection{Study variables}

\subsubsection{Dependent variable}

Sexual harassment(physical, verbal and nonverbal sexual harassments)

\subsubsection{Independent variable} Psychological distress

\section{Demographic variable of the study}

Age

Department

Year of the study

Place of origin

Marital status

\subsection{Data collection method and procedure}

Data was collected by a pre-tested and self-administered questionnaire. The questionnaire contained three sections. The first section contained items on demographic information. The second part consist sexual harassment and the last section, adopted from WHO consisted of a standardized self-reported questionnaire (SRQ-20) for measuring psychological distress. The questionnaire is prepared in English translated to Amharic then back translated to English language for its consistency by two different individuals who speak both English and Amharic.

\subsection{Operational definitions and definition of terms}

Sexual harassment in the current research is defined as any unwanted and unwelcomed verbal or physical sexual advance which is offensive to the person at whom they are directed or which cause a person discomfort or humiliation.

Psychological distress is a discomforting, emotional, and a unique state experienced by an individual, in response to a specifics stressor or demand, that result in harm, either temporary, or permanent, to the person.

Sexual harassment consequences are any reproductive health, psychological or academic effects of sexual harassment that happened on the victims. 
Perpetuator the person who committed sexual harassment on the victim

\subsection{Data analysis}

After collection the data was checked for completeness, cleaned, coded, entered and was analyzed using SPSS-21 version software. Descriptive statistics including frequencies, percentages, mean, and standard deviations was used to describe the findings. The presence of association was expressed using bivariate analysis and associations with p-value $<0.05$ will be considered as statistically significant.

\subsection{Data quality management}

Data quality assurance mechanisms was carefully developed and implemented in questionnaire designing, data collection, and data entry and data analysis. The questionnaire was pre-tested on $5 \%$ of sample size on other students but that has similar socio-demographic characteristics and based on the findings of the pre-test, necessary corrections was incorporated to the questionnaire prior to the actual data collection. Data collectors was expiation on how to fill questionnaire. The collected data was checked by principal investigator on daily basis for any incompleteness and inconsistency. Each questionnaire was given a unique identification number that was considered as one variable in the data entry in to computer. Data cleaning was given due attention to identify errors.

The self-administered questionnaire is inherently problematic as students may not give valid and reliable information. To minimize this problem, different strategies including collection of data by group members and giving clarification if something is unclear was used. Moreover, the objective of the study was clearly communicated to the study participants orally and in written form, and good rapport was also established in order to maximize the trustworthiness of the information students provided.

\subsection{Ethical considerations}

Ethical clearance and approval for the study was obtained from HCHS research ethical review committee and an official letter of cooperation was written to the respective departments.

The purpose of the study was explained for study participants in the language they easily understand (Amharic) and written or oral consent was obtained from respondents. Respondents who are not willing to be involved in the study or those who want to stop filling the questionnaire at any time have the right to opt out of the study at any point in time. The instruments was translated from English into Amharic language and was reviewed by a group of language experts for meaning, comprehensibility and cultural appropriateness, and back-translated into English for verification. The issue of sexual harassment is naturally a sensitive issue, hence, the confidentiality of information regarding participants that was involved in this study was maintained to the maximum extent as much as possible along with keeping all respondents information within the study site and avoidance of identifying study participants by name or personal identifiers on any documentation, report or publication resulting from data collected in this study.

\subsection{Pretest}

Pretest was conducted on 5\% of total sample sizes on other subjects who share similar socio demographic characteristics with study participants in TTC College before actual data collection period.

\subsection{Dissemination plan of results}

The finding will be presented to Hawassa College of health science community. It will be also communicated to the local health planners and other relevant stakeholders like women affair Bureau, SNNPR Health Bureau and other organizations working gender or reproductive health to take recommendations into consideration of planning process.

The results of this study will be disseminated through presentation for the public, putting the printed final manuscript in library and by publishing the results in accessible reprint and internet media such journals, proceeding.

\section{RESULT}

\subsection{Socio-demographic characteristics}

A total of $385(100 \%)$ standouts were participated in the study giving $385(100 \%)$ response rate. The minimum and maximum age of the responds was 17 and 22year respectively. Based on the collected data, among the total respondents $110(28.6 \%)$ were accounting students and followed by BSc nurse students 108(28.1). Majority of the students who were $169(43.9 \%)$ were first year students, followed by $111(28.8 \%)$ second year students and the rest $105(27.3 \%)$ were third year and fourth. Majority of them who were $267(69.4 \%)$ of the females students were from urban areas and whereas the rest from rural areas. And the majority of them who were $360(93.5 \%)$ of the girls are unmarried and the rest $25(6.5 \%)$ are married. The majority of the students $187(48.6 \%)$ average monthly income/pocket money was $>1000$ ETB, 120(31.2\%) were 500-999 ETB and 78(20.3\%) were < 500 ETB. The 
majority of the participants $231(60.0 \%)$ living arrangement were alone, followed by $82(21.3 \%)$ living with relatives. See the Table 2

Table 2: Socio-demographic characteristics of regular, undergraduate female students of Hawassa Pharma College, Southern Ethiopia October, 2018

\begin{tabular}{|c|c|c|c|}
\hline Demographic Variables & Category & Frequency & Percent \\
\hline \multirow[t]{6}{*}{ Age in years } & 17 & 10 & 2.6 \\
\hline & 18 & 44 & 11.4 \\
\hline & 19 & 97 & 25.2 \\
\hline & 20 & 118 & 30.6 \\
\hline & 21 & 76 & 19.7 \\
\hline & 22 & 40 & 10.4 \\
\hline \multirow[t]{5}{*}{ Departments } & Pharmacy & 100 & 26.0 \\
\hline & BSc nurse & 108 & 28.1 \\
\hline & Health officer & 61 & 15.8 \\
\hline & Accounting & 110 & 28.6 \\
\hline & Business management & 6 & 1.6 \\
\hline \multirow{4}{*}{ Years of study } & ${ }_{1}$ st year & 169 & 43.9 \\
\hline & $2^{\text {nd }}$ year & 111 & 28.8 \\
\hline & $3^{\mathrm{rd}}$ year & 50 & 13.0 \\
\hline & $4^{\text {th }}$ year & 55 & 14.3 \\
\hline \multirow{2}{*}{ Place of birth } & Urban & 267 & 69.4 \\
\hline & Rural & 118 & 30.6 \\
\hline \multirow{4}{*}{ Marital status } & Single & 360 & 93.5 \\
\hline & Married & 25 & 6.5 \\
\hline & Divorced & 0 & 0 \\
\hline & Widowed & 0 & 0 \\
\hline \multirow{3}{*}{ Average monthly income/pocket money } & $<500$ & 78 & 20.3 \\
\hline & $500-999$ & 120 & 31.2 \\
\hline & $>1000$ & 187 & 48.6 \\
\hline \multirow{5}{*}{ Current living arrangement of respondent } & With both parents & 58 & 15.3 \\
\hline & With relative & 82 & 21.3 \\
\hline & Alone & 231 & 60.0 \\
\hline & With husband or partner & 10 & 2.6 \\
\hline & With father or Mather & 3 & 0.8 \\
\hline
\end{tabular}

